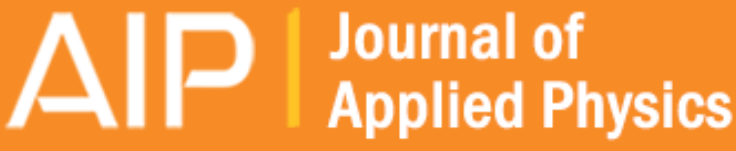

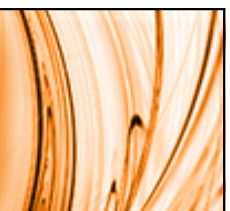

\section{In-situ transmission electron microscopy growth of nanoparticles under extreme}

conditions

F. P. Luce, E. Oliviero, G. de M. Azevedo, D. L. Baptista, F. C. Zawislak, and P. F. P. Fichtner

Citation: Journal of Applied Physics 119, 035901 (2016); doi: 10.1063/1.4940158

View online: http://dx.doi.org/10.1063/1.4940158

View Table of Contents: http://scitation.aip.org/content/aip/journal/jap/119/3?ver=pdfcov

Published by the AIP Publishing

\section{Articles you may be interested in}

Nucleation and growth of Pt nanoparticles on reduced and oxidized rutile TiO2 (110)

J. Chem. Phys. 141, 214702 (2014); 10.1063/1.4902249

In-situ energy dispersive $x$-ray diffraction study of the growth of $\mathrm{CuO}$ nanowires by annealing method J. Appl. Phys. 114, 144303 (2013); 10.1063/1.4824177

In situ transmission electron microscopy studies of the kinetics of Pt-Mo alloy diffusion in ZrB2 thin films Appl. Phys. Lett. 103, 121601 (2013); 10.1063/1.4820581

Control of silicon nanoparticle size embedded in silicon oxynitride dielectric matrix J. Appl. Phys. 114, 033528 (2013); 10.1063/1.4816042

In-situ transmission electron microscopy of partial-dislocation glide in $4 \mathrm{H}-\mathrm{SiC}$ under electron radiation Appl. Phys. Lett. 101, 042102 (2012); 10.1063/1.4737938

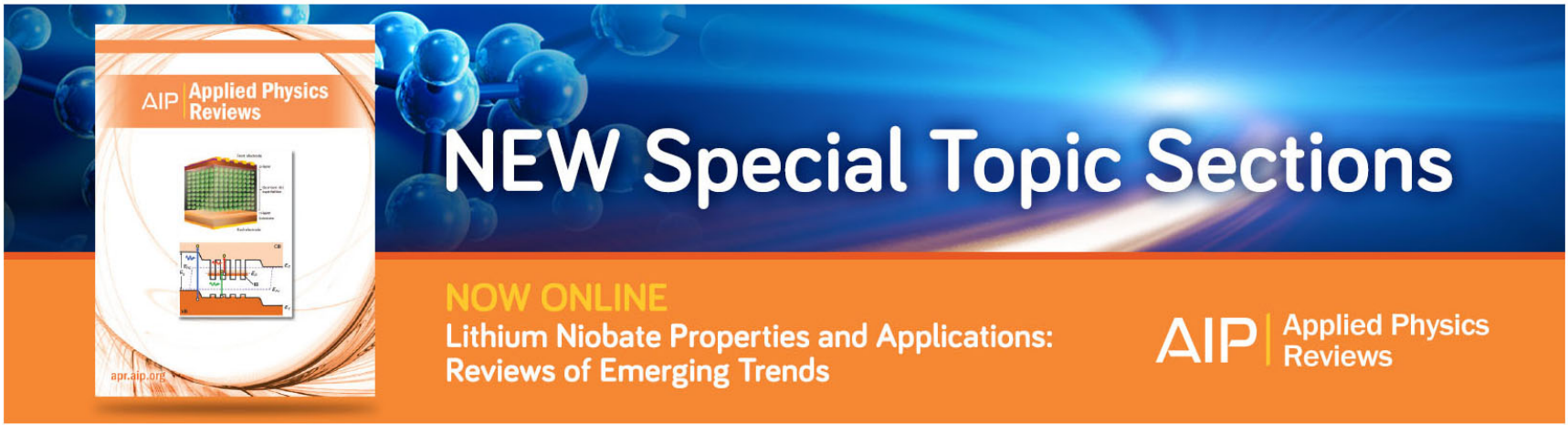




\title{
In-situ transmission electron microscopy growth of nanoparticles under extreme conditions
}

\author{
F. P. Luce, ${ }^{1}$ E. Oliviero, ${ }^{2}$ G. de M. Azevedo, ${ }^{1}$ D. L. Baptista, ${ }^{1}$ F. C. Zawislak, ${ }^{1}$ \\ and P. F. P. Fichtner ${ }^{1,3}$ \\ ${ }^{1}$ Instituto de Física, Universidade Federal do Rio Grande do Sul, Porto Alegre 91501-970, Brazil \\ ${ }^{2}$ Centre de Spectrométrie Nucléaire et de Spectrométrie de Masse (CSNSM), CNRS-IN2P3-Université \\ Paris-Sud, 91405 Orsay-Campus, France \\ ${ }^{3}$ Escola de Engenharia, Universidade Federal do Rio Grande do Sul, Porto Alegre 91501-970, Brazil
}

(Received 26 October 2015; accepted 5 January 2016; published online 15 January 2016)

\begin{abstract}
The formation and time resolved behavior of individual $\mathrm{Pb}$ nanoparticles embedded in silica have been studied by in-situ transmission electron microscopy observations at high temperatures $\left(400-1100^{\circ} \mathrm{C}\right)$ and under $200 \mathrm{keV}$ electron irradiation. It is shown that under such extreme conditions, nanoparticles can migrate at long distances presenting a Brownian-like behavior and eventually coalesce. The particle migration phenomenon is discussed considering the influence of the thermal energy and the electron irradiation effects on the atomic diffusion process which is shown to control particle migration. These results and comparison with ex-situ experiments tackle the stability and the microstructure evolution of nanoparticles systems under extreme conditions. It elucidates on the effects of energetic particle irradiation-annealing treatments either as a tool or as a detrimental issue that could hamper their long-term applications in radiation-harsh environments such as in space or nuclear sectors. (C) 2016 AIP Publishing LLC.
\end{abstract}

[http://dx.doi.org/10.1063/1.4940158]

\section{INTRODUCTION}

Due to their large surface area to volume ratio, nanoparticles (NPs) are intrinsically in a non-thermodynamic equilibrium state. It is well known that as the NP decreases in size, the effects due to this ratio significantly affect their physical and chemical properties including phase stability and melting temperatures. ${ }^{1,2}$ Melting point depression with decreasing radius is a common behavior observed for individual NPs and successfully explained via thermodynamic approaches. ${ }^{3}$ The melting temperature of $\mathrm{Au}^{4}$ and $\mathrm{Sn}^{5}$ nanoparticles $\left(\mathrm{T}_{\mathrm{mp}}\right)$ with a radius about $2 \mathrm{~nm}$, for example, is approximately a factor of 2 smaller than the melting temperature for bulk $\left(\mathrm{T}_{\mathrm{mb}}\right)$ (i.e., $\mathrm{T}_{\mathrm{mp}} / \mathrm{T}_{\mathrm{mb}} \approx 0.5$ ). On the other hand, melting temperature elevation reaching $\mathrm{T}_{\mathrm{mp}} / \mathrm{T}_{\mathrm{mb}} \approx 2$ or 3 has also been detected for special cases (e.g., $\mathrm{Pb},{ }^{6} \mathrm{Sn}^{7,8}$ and $\mathrm{Ga}^{9}$ ). As a system, the particles tend to coarsen in order to minimize the total free energy via processes mostly driven by the reduction of the total particle/matrix interface area, promoting particle growth and lowering their number density. For NPs embedded in a solid matrix, thermally driven coarsening is the most common process to tune NP sizes and therefore the system properties. ${ }^{10}$

In this contribution, we have used a model case system made of $\mathrm{Pb}$ nanoparticles produced by ion implantation in silica and submitted to aging, to tackle the stability and the microstructure evolution of NP systems under extreme conditions. In that purpose, in-situ transmission electron microscopy (TEM) high temperature thermal treatments have been performed. The results reveal that the $200 \mathrm{keV}$ electron beam used for the TEM analysis significantly affects the thermal evolution of the system. The phenomenon is discussed by considering electron irradiation as an additional thermodynamic parameter influencing the atomic mechanisms controlling atomic diffusion, particle nucleation, growth and coarsening processes. It is shown that effects of energetic particle irradiation coupled to annealing treatments could hamper or enhance NP system long-term applications in radiation-harsh environments such as in space ${ }^{11}$ or nuclear ${ }^{12}$ sectors.

\section{EXPERIMENTAL METHODS}

$\mathrm{Pb} \mathrm{NP} /$ silica matrices were made by implanting $\mathrm{Pb}^{+}$ions in $165 \mathrm{~nm}$ thick $\mathrm{SiO}_{2} / \mathrm{Si}(001)$ films thermally grown in dry oxygen atmosphere. Implantations were performed at room temperature (RT) with an energy $\mathrm{E}=300 \mathrm{keV}$ and a fluence $\mathrm{f}=5$

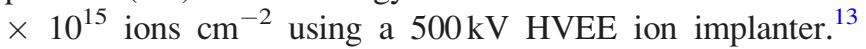
Following the work of Luce et al., ${ }^{6}$ some samples were aged post implantation by a low temperature $\left(200^{\circ} \mathrm{C}\right)$ long time $(100 \mathrm{~h})$ aging treatment in open atmosphere, in order to form small clusters and/or NPs with specific characteristics. ${ }^{6}$

Rutherford Backscattering (RBS) measurements were performed on as-implanted, aged, and aged ex-situ annealed matrices in a 3 MV HVEE Tandetron accelerator ${ }^{13}$ using a 1.2 $\mathrm{MeV} \mathrm{He}^{+}$beam, in order to evaluate $\mathrm{Pb}$ losses and redistribution.

For TEM experiments, wedge shape cross-section samples were thinned up to electron transparency using the tripod polishing technique, omitting the final ion milling step to avoid the introduction of irradiation type defects during sample preparation.

In-situ TEM experiments on aged $\mathrm{NP} /$ silica matrices were carried out at JANNuS ${ }^{14}$ using a Tecnai $\mathrm{G}^{2} 20$ apparatus operating at $200 \mathrm{kV}$ with a beam current of about $10 \mathrm{nA}$. The sample temperature was ramped to $1100^{\circ} \mathrm{C}$ in $15 \mathrm{~min}$ according to Fig. 1 and kept at this temperature for $1 \mathrm{~h}$ using 


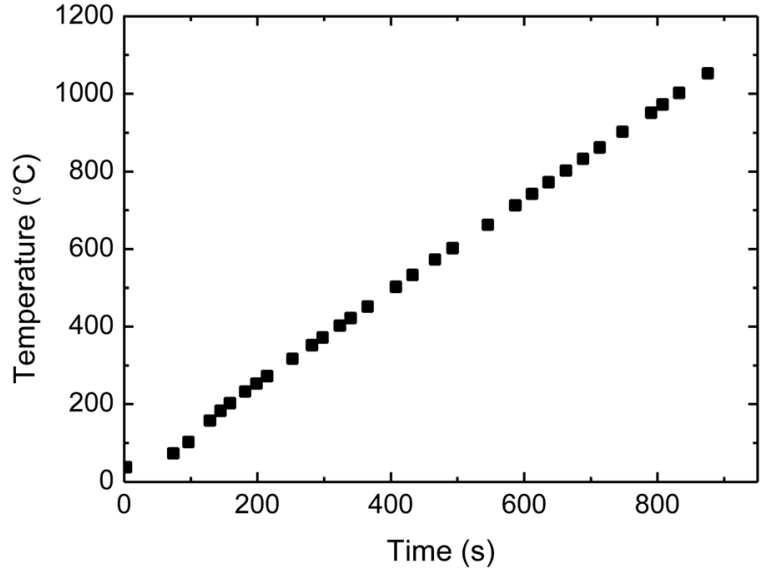

FIG. 1. Annealing ramp used in the in-situ TEM experiment.

a single-tilt Gatan heating sample holder. The in-situ TEM annealing experiments were digitally recorded in real time at high frame rate (30 fps) using a Gatan Orius SC200 2k × $2 \mathrm{k}$ CCD camera.

Ex-situ observations on as-implanted and aged NP/silica matrices were performed either at $200 \mathrm{kV}$ using a JEM 2010 microscope from CME-UFRGS ${ }^{15}$ or at $300 \mathrm{kV}$ using a Cscorrected TITAN 80/300 microscope from INMETRO. ${ }^{16}$

\section{RESULTS AND DISCUSSIONS}

\section{A. Characterization of aged samples}

Aged samples have been chosen as a starting material because the nanoparticles formed during this low temperature long time annealing present a better thermal stability when compared with samples synthesized via the usual implantation plus high temperature annealing route. ${ }^{6}$ Figure 2(a) shows $\mathrm{Pb}$ concentration depth profiles extracted from RBS measurements of as-implanted and aged samples. The difference in area under these curves shows that the aging process causes a loss of $\mathrm{Pb}$ of about $15 \%$ as compared with the asimplanted content. The curves are superposed to a conventional cross-section TEM micrograph of the aged sample, illustrating the presence of NPs (areas of darker contrast) with a mean diameter of $\phi_{\mathrm{m}}=4.2 \pm 0.8 \mathrm{~nm}$ located around the peak maxima. The $\mathrm{Pb}$ content incorporated in such NP system has been estimated previously and corresponds to about only $25 \%$ of the $\mathrm{Pb}$ atoms detected by RBS in the aged sample. ${ }^{6}$

Figure 2(b) shows a high-resolution z-contrast image generated by scanning TEM (STEM) high-angle annular dark-field (HAADF). It reveals that, in addition to the larger particles observed via conventional TEM (Figure 2(a)), the aging treatment also results in a population of subnanometric sized clusters containing $\mathrm{Pb}$ atoms. These clusters cannot be observed by conventional TEM methods. The present STEM-HAADF observations provide the first direct experimental evidence that the aging process contributes to the formation of subnanometric $\mathrm{Pb}$ rich atomic clusters. These clusters not only trap a large fraction of the $\mathrm{Pb}$ atoms (about $75 \%$ of the total implanted amount) but also appear to be more stable. ${ }^{6,8}$ This seemingly enhanced thermal stability of the $\mathrm{Pb}$ nanoclusters justifies the need to further investigate their evolution under different thermal annealing conditions and electron irradiation.

\section{B. Evolution of aged samples under ex-situ annealing}

To investigate the effect of the ex-situ annealing on aged samples, $200 \mathrm{~nm} \mathrm{SiO}_{2} / \mathrm{Si}$ substrates were implanted with $\mathrm{Pb}$ ions with a fluence of $1.25 \times 10^{16}$ ions $\mathrm{cm}^{-2}$ and then submitted to the aging treatment to form thermally stables clusters. This aged sample was then annealed ex-situ at $850^{\circ} \mathrm{C}$ and analyzed by TEM and RBS. The obtained results are summarized in Figure 3(a). The cross-section TEM micrograph shows that the small NPs (observed in Figure 2(a)) have dissolved, giving rise to the formation of fewer but larger particles, while the cluster populations seem to remain stable and therefore are not visible by conventional TEM methods. This is confirmed by the superposed concentration-depth profile determined by $\mathrm{RBS}$, demonstrating that the $\mathrm{Pb}$ content remains constant and has not re-distributed in depth. These results suggest that the $850{ }^{\circ} \mathrm{C}$ ex-situ thermal treatment leads to the formation of a reduced number of large $\mathrm{Pb}$ particles in the central region of the silica film, but the majority of the $\mathrm{Pb}$
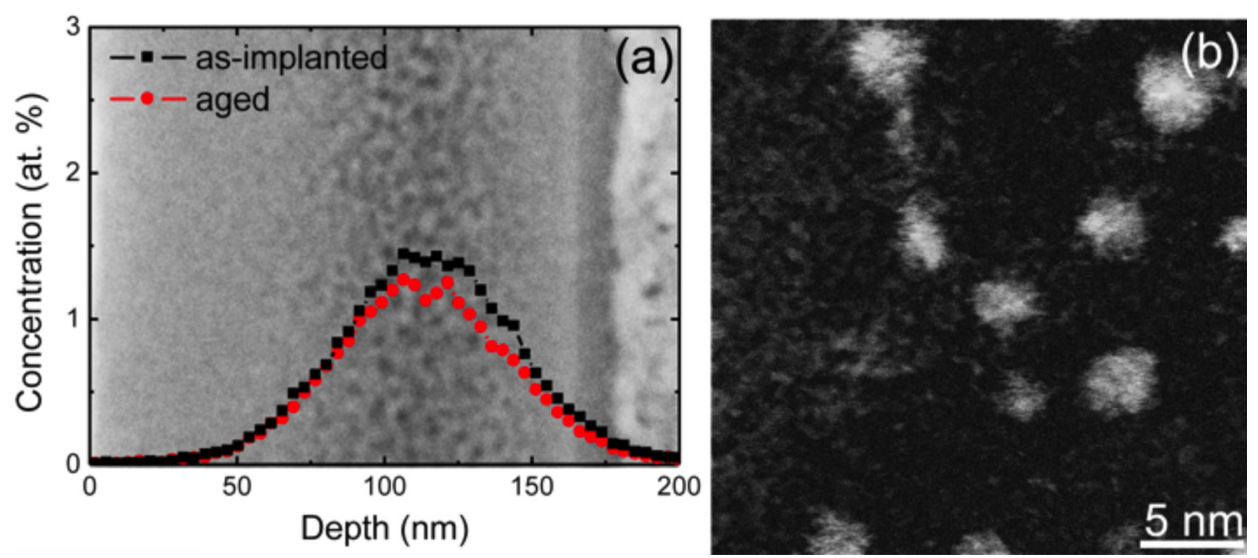

FIG. 2. (a) Concentration-depth profile obtained from RBS measurements of the as-implanted and aged samples superimposed to the TEM image of the aged sample. The total implanted fluence $\left(\mathrm{f}=5 \times 10^{15}\right.$ ions $\left.\mathrm{cm}^{-2}\right)$ is found in the as-implanted sample, while the aging treatment led to a Pb loss accompanied by the formation of small particles located in the central region of the silica film. (b) STEM-HAADF z-contrast micrograph of the aged sample, revealing that a large quantity of $\mathrm{Pb}$ (about $75 \%$ of the implanted atoms) is either atomically dispersed within the silica film or agglomerated in subnanometric sized clusters. 


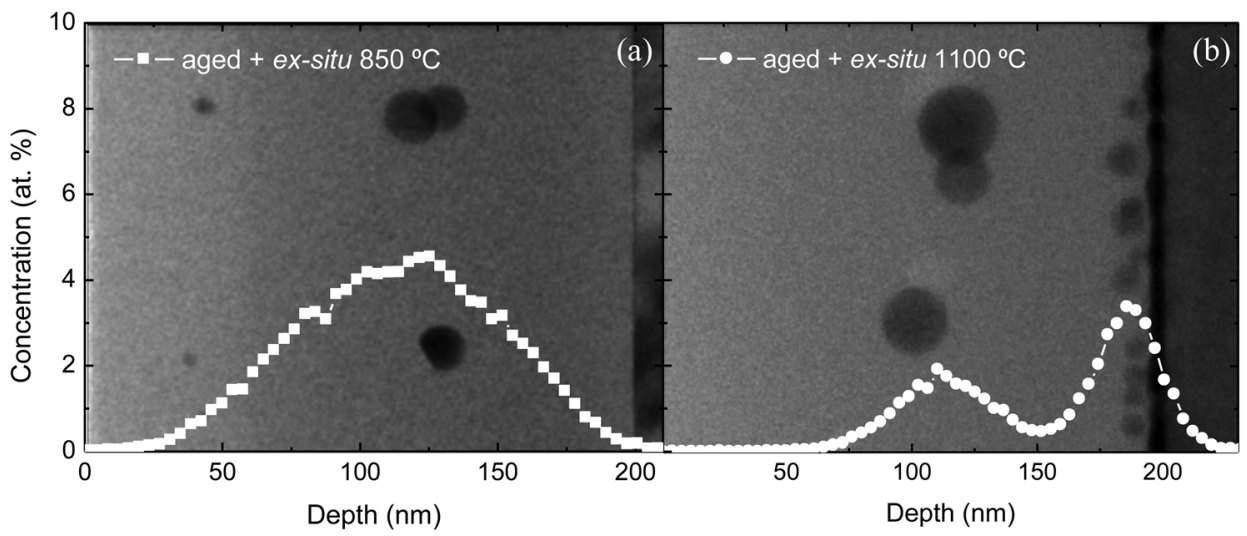

FIG. 3. Pb concentration-depth profiles obtained by RBS measurements superimposed with the TEM images of aged samples annealed ex-situ at (a) $850^{\circ} \mathrm{C}$ and (b) $1100^{\circ} \mathrm{C}$. In both cases, the implantation fluence was $1.25 \times 10^{16}$ ions $\mathrm{cm}^{-2}$.

content still remains trapped in stable clusters, not observable by conventional TEM. So, despite the higher $\mathrm{Pb}$ implantation fluence, no major evolution of the aged system has occurred up to $850^{\circ} \mathrm{C}$. Nevertheless, important changes were observed when the aged sample was subjected to ex-situ anneal at $1100^{\circ} \mathrm{C}$. According to the RBS concentration-depth profile presented in Figure 3(b), the $\mathrm{Pb}$ content that was originally located in the central region of the silica film diffused to the $\mathrm{SiO}_{2} / \mathrm{Si}$ interface. The superposed TEM micrograph suggests that the $\mathrm{Pb}$ atoms that migrated to the silica/Si interface led to the formation of bi-dimensional system of $\mathrm{Pb}$ nanoparticles. Few large $\mathrm{Pb}$ particles were yet formed in the central region of the $\mathrm{SiO}_{2}$ film mostly due to the implantation fluence $\left(1.25 \times 10^{16}\right.$ ions $\left.\mathrm{cm}^{-2}\right)$. A detailed explanation of the thermal evolution of $\mathrm{Pb}$ nanoclusters is given elsewhere. ${ }^{6}$ In the present contribution, the results of these ex-situ annealed control samples are useful for comparison purposes, to evidence the effects of the electron irradiation on their thermal stability.

\section{Evolution of aged samples under in-situ annealing}

Figure 4(a) illustrates the microstructural configuration obtained during in-situ observations at $600^{\circ} \mathrm{C}$. It shows that, under electron irradiation, there is a more intense nucleation process resulting in a high density of NPs within the silica film with mean diameter $\phi_{\mathrm{m}} \approx 7 \pm 1 \mathrm{~nm}$. It also shows that long range $\mathrm{Pb}$ redistribution has already taken place, leading to the formation of larger particles located at $\mathrm{SiO}_{2} / \mathrm{Si}$ interface. Such NPs have dimensions around 15 to $40 \mathrm{~nm}$, with a characteristic shape of a spherical dome at the silica side and a pyramidal frustum within the $\mathrm{Si}$ substrate, as characterized elsewhere. ${ }^{17}$ It is worth mention that for ex-situ treated samples, similar particles at the interface are only observed after thermal treatments at $1100^{\circ} \mathrm{C},{ }^{6,8,17}$ as illustrated in Figure 3(b). Finally, Figure 4(b) shows the transition between a region that has been under observation for several minutes (left side) and the one that has been just irradiated (right side). This observation was possible as the electron beam was preferentially focused on the left side and therefore has accelerated the coarsening process in this region. The in-situ observation reveals that the coarsening process occurs via particle migration and coalescence. As the electron beam starts to impinge on the particles on the right side, they start to migrate much faster than the larger ones at the left. The digital record of the in-situ observations (see Figure 4) shows a faster migration and coalescence behavior developing as a wave front progressing from the right to the left. These observations (relate to Figures 4(a) and 4(b)) demonstrate that electron irradiation affects both atomic and particle migration mechanisms.

During $1100^{\circ} \mathrm{C}$ in-situ annealing, different processes are observed as shown in Figure 5(a): migration and pinning at the $\mathrm{SiO}_{2} / \mathrm{Si}$ interface, migration and coalescence of $\mathrm{Pb}$ nanoparticle, and accumulation and growth of $\mathrm{Pb}$ nanoparticle at the $\mathrm{SiO}_{2} / \mathrm{Si}$ interface. Another effect of the high temperature annealing combined with the electron irradiation is the disappearance of several particles, most probably because they reach and escape from the free surfaces created by the sample cross-section geometry. This phenomenon is illustrated by the sequence of micrographs displayed in Figure 5(b). The images were extracted from the video recorded during the $1100^{\circ} \mathrm{C}$ in-

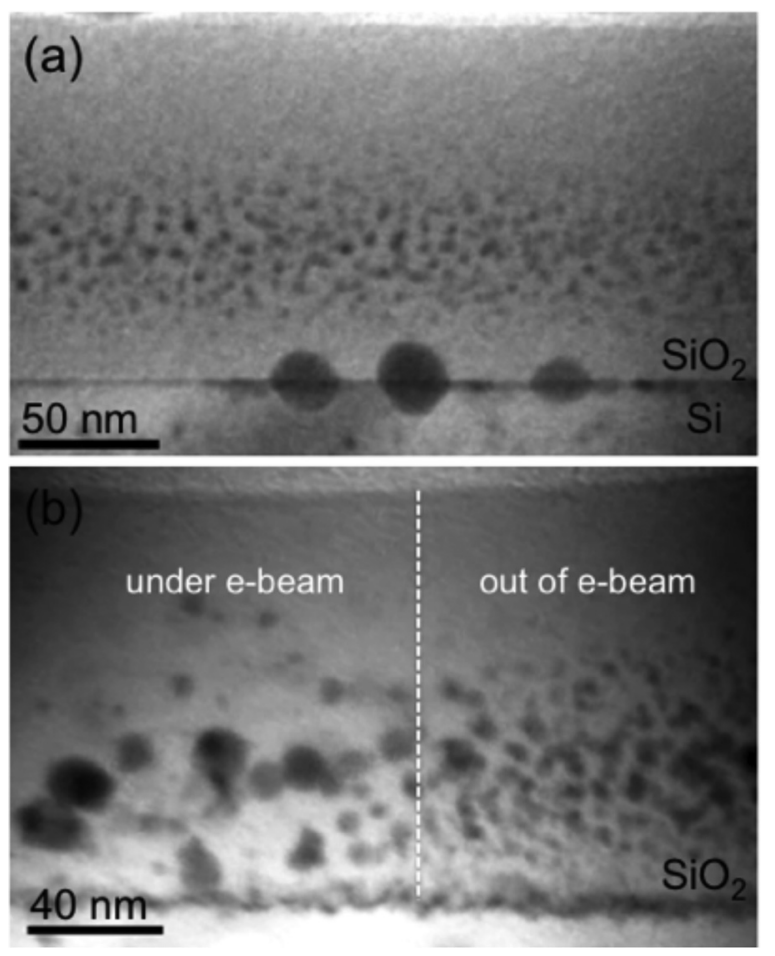

FIG. 4. In-situ evolution of the aged sample implanted at $5 \times 10^{15}$ ions $\mathrm{cm}^{-2}$. (a) Instantaneous micrograph obtained during in-situ $600^{\circ} \mathrm{C}$ thermal annealing of the aged sample showing the presence of $\mathrm{Pb} \mathrm{NPs}$ at $\mathrm{SiO}_{2} / \mathrm{Si}$ interface. (b) Irradiation effect of the TEM electron beam (e-beam) combined with $1100^{\circ} \mathrm{C}$ in-situ thermal annealing. Image extracted from the in-situ movie. (Multimedia view) [URL: http://dx.doi.org/10.1063/1.4940158.1] 

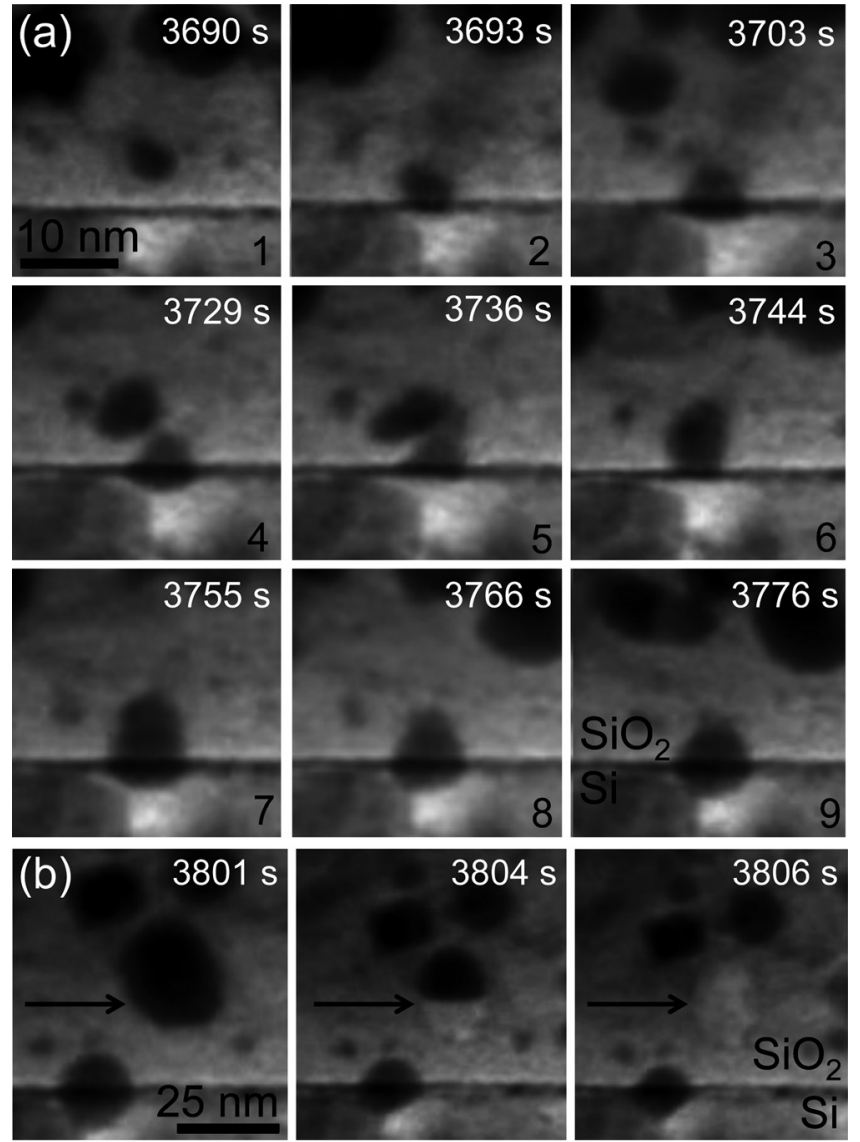

FIG. 5. (a) Sequence of micrographs from the same sample region extracted from the video recorded during in-situ $1100^{\circ} \mathrm{C}$ TEM thermal annealing after indicated time: (1) and (2) migration and pinning, (3) to (7) migration and coalescence, and (8) and (9) accumulation and growth of $\mathrm{Pb}$ nanoparticle at the $\mathrm{SiO}_{2} / \mathrm{Si}$ interface. (b) Sequence showing the evaporation of a $\mathrm{Pb}$ nanoparticle embedded in the silica layer. The micrographs were extracted from the video recorded during the $1100^{\circ}$ in-situ TEM annealing of the sample implanted with a fluence of $5 \times 10^{15}$ ions $\mathrm{cm}^{-2}$. (Multimedia view) [URL: http://dx.doi.org/10.1063/1.4940158.2]

situ TEM annealing and show the evaporation of a $\mathrm{Pb}$ nanoparticle within the silica film.

Figures 6(a) and 6(b) show in-situ TEM micrographs at $1100{ }^{\circ} \mathrm{C}$ from the same sample region but obtained at two distinct times, $8 \mathrm{~min}$ apart. Since this temperature is significantly higher than the melting temperature of bulk metallic $\mathrm{Pb}\left(327^{\circ} \mathrm{C}\right)$ or even of their bulk oxide phases $(\mathrm{PbO}$ with $\mathrm{T}_{\mathrm{m}}=888^{\circ} \mathrm{C}$ (Ref. 18) and $\mathrm{Pb}_{3} \mathrm{O}_{4}$ with $\mathrm{T}_{\mathrm{m}}=500{ }^{\circ} \mathrm{C}$ (Ref. 19)), it is assumed that the particles are in the liquid state regardless of their composition. Particle migration is fast and presents a Brownian-like behavior (see Figure 5). In addition to the particle migration and coalescence, there is the particle evaporation phenomenon, as illustrated in Figure 5(b). Therefore, the present observations cannot be directly analyzed in terms of particle size distribution parameters (mean sizes and higher momentum distributions) as predicted by standard coarsening theories. Nevertheless, the determination of the two dimensional projection of the effective migration distances $X_{\text {eff }}$ achieved by individual particles within a time interval $\Delta t$ renders the determination of the particle diffusivity $D_{p}$ by means of the random walk expression $^{20}$
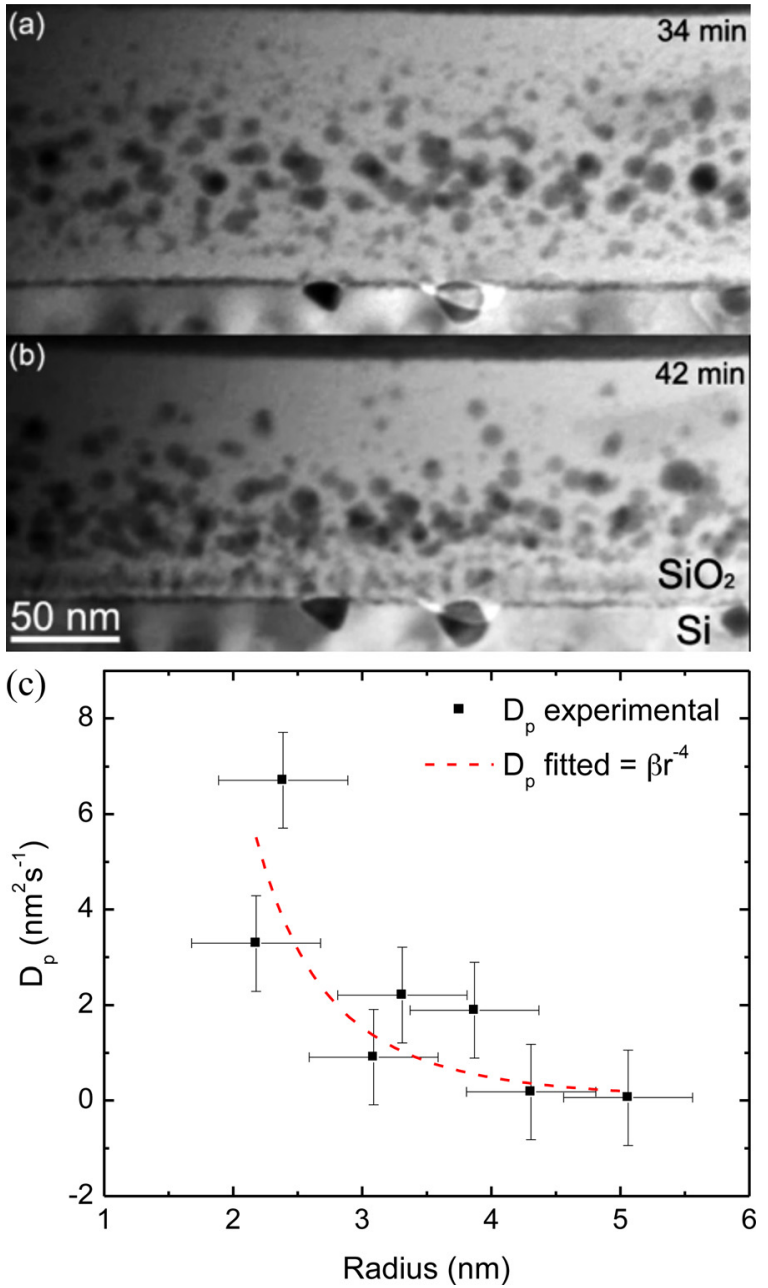

FIG. 6. Sequence of micrographs from the same sample region obtained during in-situ $1100^{\circ} \mathrm{C}$ TEM thermal annealing after (a) 34 and (b) 42 min of high temperature treatment. (c) Particle diffusivity coefficient $D_{p}$ as a function of NP radius. The data points were experimentally obtained from the video recorded during $1100^{\circ} \mathrm{C}$ in-situ thermal annealing and are consistently fitted by $D_{p}=\beta r^{-4}(\beta=124)$ suggesting that particle growth is governed by migration and coalescence processes mainly controlled by surface diffusion mechanisms. (Multimedia view) [URL: http://dx.doi.org/10.1063/1.4940158.3]

$$
X_{e f f}=\sqrt{2 D_{p} \Delta t}
$$

Figure 6(c) shows a set of measured $D_{p}$ values plotted as a function of the particle radius. The data can be consistently fitted by the expression

$$
D_{p}=\beta r^{-4}
$$

suggesting that the rearrangement of matrix atoms or molecules around the particle interface (usually referred to as surface diffusion mechanism) can be considered as the major process controlling particle migration. ${ }^{20-23}$

In order to discuss these results, it is important to establish that the present behavior is only achievable due to the unique nature of these samples. That is, the thermal aging protocol allows for the formation of more stable $\mathrm{Pb}$ atomic clusters due to the preferential formation of covalent bonds and interfaces of lowest free energy. ${ }^{6}$ Under electron irradiation, atomic redistribution and particle coarsening begin at temperatures above $450{ }^{\circ} \mathrm{C}$ and become quite evident at 
$600{ }^{\circ} \mathrm{C}$ (see Figure 4(a)). Particle migration is detected at temperatures above $900{ }^{\circ} \mathrm{C}$, but their individual movements cannot be analyzed due to the high concentration, which results in image superposition. At $1100^{\circ} \mathrm{C}$, the system becomes sufficiently dilute and the particles are large enough to allow the observation of their individual behavior. This effect is more clearly illustrated in the image sequence presented in Figure 7. The micrographs are instantaneous snapshots of the same region obtained from the video recorded during the $1100{ }^{\circ} \mathrm{C}$ in-situ TEM annealing.

The interpretation of the present results is based on the empirical evidence that, in addition to the thermal energy provided by the in-situ TEM high annealing temperatures, it is the electron irradiation that enhances the processes governing atomic diffusion and particle migration. As previously assumed, the observed particles are in the molten state and therefore can be treated as bubbles (i.e., cavities containing a fluid). Their migration mechanism is analyzed in terms of a random walk approach and correlates well with the behavior
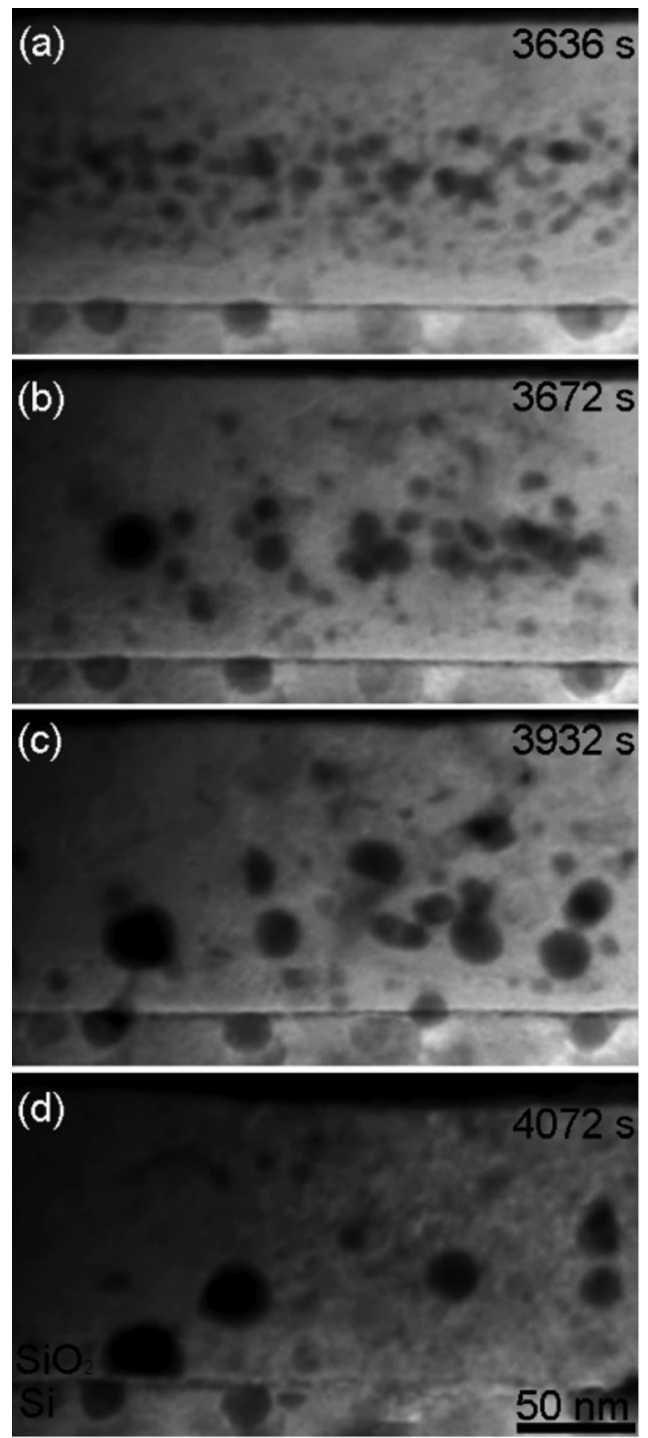

FIG. 7. Sequence of images from the same sample region extracted from the video recorded during the $1100^{\circ} \mathrm{C}$ in-situ TEM annealing showing the evolution of the nanoparticles system over time. The original sample was implanted with $5 \times 10^{15}$ ions $\mathrm{cm}^{-2}$ and aged as described previously. expected by the interface diffusion mechanism (Figure $6(\mathrm{c}))^{22,23}$

The first direct evidence of particle migration purely stimulated by electron irradiation during room temperature in-situ TEM studies has been provided by Allen et al. ${ }^{21}$ They have detected Xe solid nanoprecipitates migration in Al foils observed in high resolution TEM using a $1 \mathrm{MeV}$ accelerated electron beam, accounting migration lengths on a sub nanometer scale. They have attributed the migration to the accumulation of displacement damage within the lattice region around the bubbles.

In our case, the observations have been performed with electrons accelerated to a lower energy (200 keV). According to Ref. 24, at $200 \mathrm{keV}$, the cross-section for elastic scattering causing displacement damage is negligible for $\mathrm{Pb}$ atoms and is about $10^{6}$ times smaller than that for inelastic scattering for $\mathrm{O}$ and $\mathrm{Si}$ bulk atoms. As opposed to the case of metallic targets, the inelastic scattering process in covalent bonded materials causes ionization and adiabatic breakdown of atomic bonds (reducing the migration energy barrier for atomic diffusion.) However, it should be noted that atoms located at the interface have weaker bond energies and that under high annealing temperature $\left(1100{ }^{\circ} \mathrm{C}\right)$ they must have rather high vibration amplitudes. Therefore, the cross-section for elastic displacements must be larger and displacement effects at the interface region cannot be disregarded without more specific considerations. Hence, it is assumed that electron irradiation causes either displacement of atoms, especially at the particle-matrix interface region, or an adiabatic breakdown of atomic bonds that enhances atomic diffusion processes controlling particle migration, as evidenced by the data in Figure 6(c).

\section{CONCLUSIONS}

In summary, the present in-situ TEM study demonstrates that liquid $\mathrm{Pb}$ particles embedded in silica may coarsen via migration and coalescence. The experiments were performed at $1100{ }^{\circ} \mathrm{C}$, allowing the direct observation of migration and coalescence phenomena at relatively high rates. In particular, it is also proved that electron irradiation significantly enhances the particle migration rate. Electron irradiation effects were interpreted either in terms of atomic displacements at the interface or in terms of ionization events triggering atomic bond disruption and therefore facilitating atomic diffusion processes. An analysis of the effective particle diffusion coefficients suggests that particle migration might be controlled by interface diffusion of matrix atoms. The events observed here at high temperature conditions can, in principle, also occur at lower rates for smaller temperatures. Hence, the present findings introduce a new paradigm for the thermal evolution behavior of NP systems submitted to harsh radiation environments.

\section{ACKNOWLEDGMENTS}

The authors would like to acknowledge K. Abrams for careful reading and comments, the technicians from LIIUFRGS for the ion beam experiments, and the financial support from the Brazilian agencies CNPq and FAPERGS. 
The use of the microscopes from JANNuS, CME-UFRGS, and INMETRO is also acknowledged.

${ }^{1}$ H. A. Atwater and A. Polman, Nat. Mater. 9, 205 (2010).

${ }^{2}$ W. Skorupa, L. Rebohle, and T. Gebel, Appl. Phys. A: Mater. Sci. Process. 76, 1049 (2003).

${ }^{3}$ Q. S. Mei and K. Lu, Prog. Mater. Sci. 52, 1175 (2007).

${ }^{4}$ K. Dick, T. Dhanasekaran, Z. Zhang, and D. Meisel, J. Am. Chem. Soc. 124, 2312 (2002).

${ }^{5}$ S. L. Lai, J. Y. Guo, V. Petrova, G. Ramanath, and L. H. Allen, Phys. Rev. Lett. 77, 99 (1996).

${ }^{6}$ F. P. Luce, F. Kremer, S. Reboh, Z. E. Fabrim, D. F. Sanchez, F. C. Zawislak, and P. F. P. Fichtner, J. Appl. Phys. 109, 014320 (2011).

${ }^{7}$ G. A. Breaux, C. M. Neal, B. Cao, and M. F. Jarrold, Phys. Rev. B 71, 073410 (2005).

${ }^{8}$ F. Kremer, J. M. J. Lopes, F. C. Zawislak, and P. F. P. Fichtner, Appl. Phys. Lett. 91, 083102 (2007).

${ }^{9}$ C. Q. Sun, C. M. Li, H. L. Bai, and E. Y. Jiang, Nanotechnology 16, 1290 (2005).

${ }^{10}$ G. De Marchi, G. Mattei, P. Mazzoldi, and C. Sada, J. Appl. Phys. 92, 4249 (2002).
${ }^{11}$ C. Morioka, K. Shimazaki, S. Kawakita, M. Imaizumi, H. Yamaguchi, T. Takamoto, S.-I. Sato, T. Ohshima, Y. Nakamura, K. Hirako, and M. Takahashi, Prog. Photovoltaics 19, 825 (2011).

${ }^{12}$ B. D. Wirth, K. Nordlund, D. G. Whyte, and D. Xu, MRS Bull. 36, 216 (2011).

${ }^{13}$ See http://implantador.if.ufrgs.br for description of the implanter and accelerator.

${ }^{14}$ Y. Serruys, P. Trocellier, S. Miro, E. Bordas, M. O. Ruault, O. Kaitasov, S. Henry, O. Leseigneur, T. Bonnaillie, S. Pellegrino, S. Vaubaillon, and D. Uriot, J. Nucl. Mater. 386, 967 (2009).

${ }^{15} \mathrm{See}$ http://www.ufrgs.br/cme for description of the microscope.

${ }^{16}$ See http://www.inmetro.gov.br for description of the Cs-corrected microscope.

${ }^{17}$ D. F. Sanchez, F. P. Luce, Z. E. Fabrim, M. A. Sortica, P. F. P. Fichtner, and P. L. Grande, Surf. Sci. 605, 654 (2011).

${ }^{18} \mathrm{P}$. Patnaik, Handbook of Inorganic Chemicals (McGraw-Hill, 2002).

${ }^{19}$ J. Gavarri, J. Solid State Chem. 23, 327 (1978).

${ }^{20}$ S. K. Tyler and P. J. Goodhew, J. Nucl. Mater. 92, 201 (1980).

${ }^{21}$ C. W. Allen, R. C. Birtcher, S. E. Donnelly, K. Furuya, N. Ishikawa, and M. Song, Appl. Phys. Lett. 74, 2611 (1999).

${ }^{22}$ P. J. Goodhew and S. K. Tyler, Proc. R. Soc. London, Ser. A 377, 141 (1981).

${ }^{23}$ H. Schroeder and P. F. P. Fichtner, J. Nucl. Mater. 179-181, 1007 (1991).

${ }^{24}$ L. Reimer and H. Kohl, Transmission Electron Microscopy: Physics of Image Formation and Microanalysis (Springer, 1993). 